Journal of Animal and Veterinary Advances 11 (9): 1312-1315, 2012

ISSN: $1680-5593$

(C) Medwell Journals, 2012

\title{
Transcription Profiles of Eimeria tenella Apical Membrane Antigen Gene, Etama
}

\author{
${ }^{1}$ Nanshan Qi, ${ }^{1}$ Mingfei Sun, ${ }^{1}$ Caiyan Wu, ${ }^{1}$ Shenquan Liao, \\ ${ }^{1}$ Minna Lv, ${ }^{2}$ Xiangrui Li and ${ }^{1}$ Jianping Cai \\ ${ }^{1}$ Institute of Veterinary Medicine, Guangdong Academy of Agricultural Sciences, \\ 510640 Guangzhou, China \\ ${ }^{2}$ Department of Preventive Veterinary Medicine, College of Veterinary Medicine, \\ Nanjing Agricultural University, 210095 Nanjing, China
}

\begin{abstract}
The invasion of Apicomplaxan parasite Eimeria tenella is a multistep process, after attaching the host cell, the tight junction complex is formed by proteins secreted from apical organelles, thoptry (RONs) and microneme (Apical Membrane Antigen, AMA) between the parasite and host cell plasma membranes which is named as Moving Juction (MJ) and through which the parasite pulls itself into the host cell. In this study, researchers have used real-time quantitative RT-PCR to study the transcription profiles of Etama gene for the 1 st time on eimeria parasites. The results showed that the transcription of Etama gene reached a peak during the sporozoites stage but it was very low during all other stages which is different from other Apicomplex parasites Etamal gene. So maybe there are other AMA family proteins in the Eimeria tenella which play a key role in the different stages, respectively.
\end{abstract}

Key words: Eimeria tenella, apical membrane antigen, real-time quantitative RT-PCR, transcription, stages

\section{INTRODUCTION}

Apicomplaxan parasite Eimeria tenella is an obligate intracellular parasite which causes avian coccidiosis and shares largely conserved invasion mechanism with other Apicomplaxan parasites including Toxoplasma gondii and the malaria parasite Plasmodium falciparum, etc. (Levine, 1988). It causes 30-100\% morbidity and 80\% mortality in the case of no any measures on the prevention (Dalloul and Lillehoj, 2006). Recent date indicate that about $£ 1.5$ billion global costs annually (Shirley et al., 2005).

The apicomplxan parasites have a highly conserved invasion mechanism which is a multistep process (Dubremetz et al., 1998). After attaching the host cell, some invasion-associated proteins are secreted from apical secretory organelles including M Cs, AMA1, ROPs and RONs, etc. (Cerede et al., 2005; Igonet et al., 2006; Nichols et al., 1983; El-Hajj et al., 2007). After being mediated by these proteins, the parasites penetrate into host cell and establish the parasitic life in a membranebound structure called the Parasitophorous Vacuole (PV) (Mercier et al., 2005).

Apical Membrane Antigen (AMA) is a kind of transmembrane protein which is identified as a conserved antigenic protein in the aipcomplexan parasites (Beghetto et al., 2005). Recently, lots of studies have being reported about the function of AMA and they found that AMA was localized to the entire surfaces of extracellular parasites and to the surface of host cell just prior to invasion (Richard et al., 2010).

It can form a ring structure with rhoptry neck proteins during invasion which is termed Moving Juction $(\mathrm{MJ})$, a tight connection between parasite and the membranes of host cell and the parasite penetrate into host cell through this ring (Straub et al., 2009). So, the AMA plays a very important role during the parasite invasion but there are limited reports about AMA in Eimeria tellena.

In this study, to clone Eimeria tenella apical membrane antigen Etama gene and study the transcription profiles of Etama gene during the different development stages of Eimeria tenella. The sequence encoding Etama protein were amplified by RT-PCR from Eimeria tenella (Guangdong strain) total RNA template. The parasites at different developmental stages were harvested and their total RNA were substracted by real-time PCR using Etactin gene as a reference for establishing standard curves to evaluate the copy number of Etama genes.

Corresponding Author: Xiangrui Li, Department of Preventive Veterinary Medicine, College of Veterinary Medicine, Nanjing Agricultural University, 210095 Nanjing, China 


\section{MATERIALS AND METHODS}

Parasites and preparetion of template cDNA: The fresh Eimeria tenella oocysts (Guangdong strain) were used in all experiments. Oocysts, second generation merozoites and sporozoites were purified as described previously (Hofmann and Raether, 1990; Xie et al., 1994). Total RNA was isolated using TRIzol ${ }^{\circledR}$ Reagent (Invitrogen acquires Life Technologies Inc.) RNA isolation protocol and treated with DNase (Promega). The first strand cDNA of samples was synthesized from the samples total RNA in different stages with PrimeScriptTM RT reagent kit Perfect Real-time (TAKaRa).

Real-time quantitative transcript analysis: Transcription of Etama was evaluated in the different stages of Eimeria tenella by quantitative real-time Reverse TranscriptionPCR (RT-PCR) using SYBR ${ }^{\circledR}$ Premix Ex Taq ${ }^{\text {TM }}$ (TaKara) and a LightCycle 1.5 System (Roche Diagnostics) and $1 \mu \mathrm{L}$ cDNA was used in each $20 \mu \mathrm{L}$ reaction, three replicate reactions were performed for each sample. As a control, transcription of Etactin was also evaluated. Five sporozoite cDNA samples were prepared by 10 fold Serial Dilution Method which was used to make a standard curve to evaluate the amplification Efficacy (E) of Etactin and Etama gene. The specific primers were created using the Primer Premier 5.0 for the Etama (product size is $125 \mathrm{bp}$ ) and Etactin (product size is $305 \mathrm{bp}$ ): $\mathrm{F}_{\text {actin: }} 5^{\prime}-$ CACCACCGCCGAGAAAGA-3' $\mathrm{R}_{\text {actin }}$ : 5'-GAACAACAT

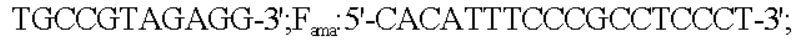
$\mathrm{R}_{\mathrm{ama}}$ : 5'-CGCACTTGCTGCCGTCTT-3' and the primer concentration were optimized by spanning the terminal concentration range of $100 \mathrm{nM}$ to $2 \mu \mathrm{M}$ using conventional PCR. The date analysis was carried out with following equation:

$$
\text { Ratio }_{\text {(testrirefence) }}=\mathrm{E}_{\text {refrence }}{ }^{\Delta \mathrm{CT}} / \mathrm{E}_{\text {test }}{ }^{\Delta \mathrm{CT}}
$$

\section{RESULTS AND DISCUSSION}

The optimal primer concentration for real time qRTPCR: The optimal primer concentrations were $500 \mathrm{nM}$, respectively in which condition, there was only peculiar PCR amplification product was identified by PCR and there was no non-peculiar band and the primer dimmers (Fig. 1).

Generation of standard curve: The standard curves were drawn according to the results of amplification of standard samples (Fig. 2) and the amplification efficiencies for Etactin and Etama of the real-time quantitative PCR Method were 2.03 and 1.93 , respectively which showed that the genes were well amplified under this condition.

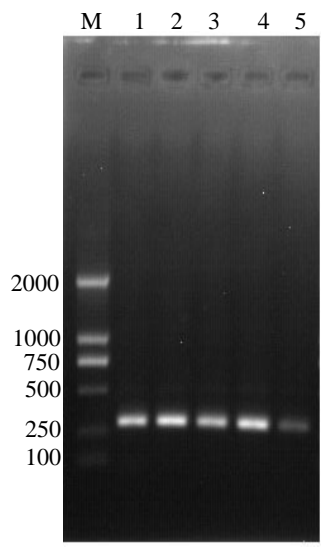

Etactin primer

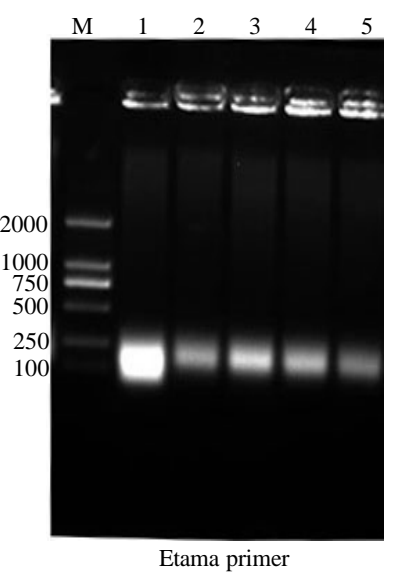

Fig. 1: Optimization of primer concentration for real time qRT-PCR; the primer concentration were optimized by spanning the terminal concentration range of $100 \mathrm{nM}$ to $2 \mu \mathrm{M}$ using conventional PCR. The optimal primer concentrations were $500 \mathrm{nM}$, respectively; M: DNA Marker DL 2000; 1:2 and 2:1 $\mu \mathrm{M} ; 3: 500 ; 4: 250$ and 5:100 nM

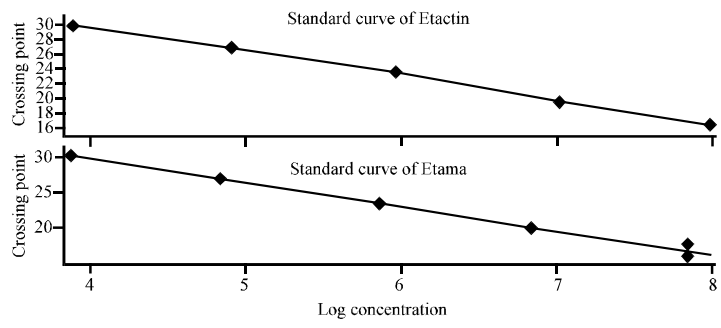

Fig. 2: The sample standard curve in real time q-PCR; five sporozoite cDNA samples were prepared by 10 fold Serial Dilution Method which was used to make a standard curve to evaluate the amplification Efficacy (E) of Etactin and Etama gene. The amplification efficiencies for Etactin and Etama of the real-time quantitative PCR Method were 2.03 and 1.93 , respectively

Analysis of Etama transcription: The Etama transcription peaks at the sporozoite, the Etactin transcription as a control (Fig. 3) and it was very low during all other stages which is different from other apicomplex parasites Etamal gene. In this study, we characterized the transcription of Etama in various developmental stages and we found the transcription of Etama gene was the highest regulated at the sporozoite stage. It was first time to use real-time quantitative PCR Method for analysis of the Eimeria tellena gene transcription in various developmental stages and the method proved to be a highly effective way to study the dynamic changes of interesting genes transcription. 


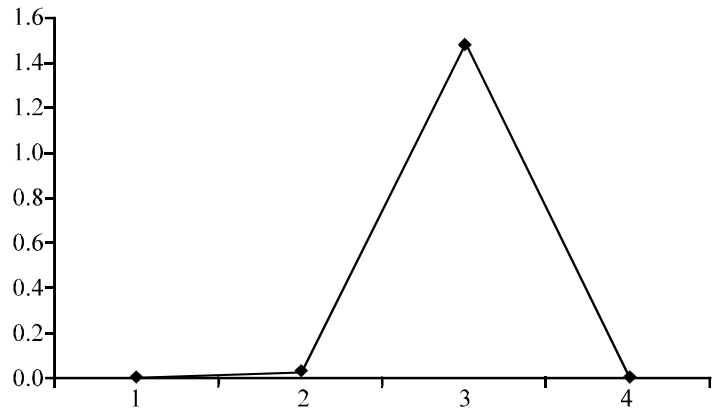

Fig. 3: The transcription of Etama in various developmental stages. The Etama transcription peaks at the sporozoite, the Etactin transcription as a control; 1: unsporulated oocysts; 2: sporulated oocysts; 3 : sporozoites; 4: merozoites

In the previous study of other apicomplexan protozoa, Apical Membrane Antigen 1 (AMA1) and Rhoptry Neck proteins (RON2, RON4, RON5 and RON8) were thought to interact with each other as a complex which was named as Moving Juction (MJ) and involved in parasite invasion of host cells (Cao et al., 2009; Alexander et al., 2006; Proellocks et al., 2009; Straub et al., 2011). For Eimeria tenella parasites, there are two important invasion stages: sporozoite and merozoite stages. But the dates in this study showed that the Etama gene transcription peaked only at the sporozoite stage, it was very low in the merozoite stage and Etron 2 gene transcription was similar in these two stages which demonstrated either Etama protein maybe not necessary for parasite invasion of host cells or there were some other proteins played a similar role as Etama in the merozoite stage.

\section{CONCLUSION}

In this study combining the results of Proteomic comparison of four Eimeria tenella life cycle stages which found there were two Etama proteins, Etamal, Etama2 and Etamal was found only in merozoites, Etama2 was only found in sporozoites (Lal et al., 2009), we can presume that Etama is necessary for Eimeria tenella parasites invasion and there are different kinds of Etama proteins play a similar role in different invasion stages.

\section{ACKNOWLEDGEMENTS}

This research was supported by a NSFC grants (No.: 30471300 and U0831004 to JC) international cooperating project from the Guangdong Science and
Technology Department (No.: 2008A050200015), NSF grant of Guangdong province (No.: 1045106001006126 ) and The President's Funds of Guangdong Academy of Agricultural Sciences (No.: 201014 and 201115). Nanshan Qi and Mingfei Sun contributed equally to this research.

\section{REFERENCES}

Alexander, D.L., S. Arastu-Kapur, J.F. Dubremetz and J.C. Boothroyd, 2006. Plasmodium falciparum AMA1 binds a rhoptry neck protein homologous to TgRON4, a component of the moving junction in Toxoplasma gondii. Eukaryot. Cell, 5: 1169-1173.

Beghetto, E., H.V. Nielsen, P. Del Porto, W. Buffolano and S. Guglietta, 2005. A combination of antigenic regions of Toxoplasma gondii microneme proteins induces protective immunity against oral infection with parasite cysts. J. Infect. Dis., 191: 637-645.

Cao, J., O. Kaneko, A. Thongkukiatkul, M. Tachibana and H. Otsuki et al., 2009. Rhoptry neck protein RON2 forms a complex with microneme protein AMA1 in Plasmodium falciparum merozoites. Parasitol. Int., 58: 29-35.

Cerede, O., J.F. Dubremetz, M. Soete, D. Deslee, H. Vial, D. Bout and M. Lebrun, 2005. Synergistic role of micronemal proteins in Toxoplasma gondii virulence. J. Exp. Med., 201: 453-463.

Dalloul, R.A. and H.S. Lillehoj, 2006. Poultry coccidiosis: Recent advancements in control measures and vaccine development. Expert Rev. Vaccines, 5: 143-163.

Dubremetz, J.F., N. Garcia-Reguet, V. Conseil and M.N. Fourmaux, 1998. Apical organelles and host-cell invasion by Apicomplexa. Int. J. Parasitol., 28: 1007-1013.

El-Hajj, H., M. Lebrun, M.N. Fourmaux, H. Vial and J.F. Dubremetz, 2007. Inverted topology of the Toxoplasma gondii ROP5 rhoptry protein provides new insights into the association of the ROP 2 protein family with the parasitophorous vacuole membrane. Cell Microbiol., 9: 54-64.

Hofmann, J. and W. Raether, 1990. Improved techniques for the in vitro cultivation of Eimeria tenella in primary chick kidney cells. Parasitol. Res., 76: 479-486.

Igonet, S., B.V.L. Normand, G. Faure, M.M. Riottot, C.H. Kocken, A.W. Thomas and G.A. Bentley, 2006. Cross-reactivity studies of an anti-Plasmodium vivax apical membrane antigen 1 monoclonal antibody: Binding and structural characterisation. J. Mol. Biol., 366: 1523-1537. 
Lal, K., E. Bromley, R. Oakes, J.H. Prieto and S.J. Sanderson et al., 2009. Proteomic comparison of four Eimeria tenella life-cycle stages: Unsporulated oocyst, sporulated oocyst, sporozoite and secondgeneration merozoite. Proteomics, 9: 4566-4576.

Levine, N.D., 1988. Progress in taxonomy of the apicomplexan protozoa. J. Eukaryotic Microbiol., 35: 518-520.

Mercier, C., K.D. Adjogble, W. Daubener and M.F. Delauw, 2005. Dense granules: Are they key organelles to help understand the parasitophorous vacuole of all apicomplexa parasites? Int. J. Parasitol., 35: 829-849.

Nichols, B.A., M.L. Chiappino and G.R. O'Connor, 1983. Secretion from the rhoptries of Toxoplasma gondii during host-cell invasion. J. Ultrastruct. Res., 83: 85-98.

Proellocks, N.I., L.M. Kats, D.A. Sheffield, E. Hanssen, C.G. Black, K.L. Waller and R.L. Coppel, 2009. Characterisation of PfRON6, a Plasmodium falciparum rhoptry neck protein with a novel cysteine-rich domain. Int. J. Parasitol., 39: 683-692.
Richard, D., C.A. MacRaild, D.T. Riglar, J.A. Chan and M. Foley et al., 2010. Interaction between Plasmodium falciparum apical membrane antigen 1 and the rhoptry neck protein complex defines a key step in the erythrocyte invasion process of malaria parasites. J. Biol. Chem., 285: 14815-14822.

Shirley, M.W., A.L. Smith and F.M. Tomley, 2005. The biology of avian Eimeria with an emphasis on their control by vaccination. Adv. Parasitol., 60: 285-330.

Straub, K.W., E.D. Peng, B.E. Hajagos, J.S. Tyler and P.J. Bradley, 2011. The moving junction protein RON8 facilitates firm attachment and host cell invasion in Toxoplasma gondii. PLoS Pathog.

Straub, K.W., S.J. Cheng, C.S. Sohn and P.J. Bradley, 2009. Novel components of the Apicomplexan moving junction reveal conserved and coccidiarestricted elements. Cell Microbiol., 11: 590-603.

Xie, H.L., M.Q. Xie, H.X. Wu, X.Y. Peng, L.N. Wen and J.F. Zhang, 1994. Effects of media and their components on cell culture of Eimeria tenella. Poceedings of the 2nd Asian Conference on Coccidiosis, November 25-28, 1994, Guangzhou, China, pp: 99-1091. 